\title{
Mapping Chinese Rice Suitability to Climate Change
}

\author{
Tianyi Zhang ${ }^{1} \&$ Xiaoguang Yang ${ }^{2}$ \\ ${ }^{1}$ State Key Laboratory of Atmospheric Boundary Layer Physics and Atmospheric Chemistry, Institute of \\ Atmospheric Physics, Chinese Academy of Sciences, Beijing, China \\ ${ }^{2}$ College of Resources and Environmental Sciences, China Agricultural University, Beijing, China \\ Correspondence: Xiaoguang Yang, College of Resources and Environmental Sciences, China Agricultural \\ University, Beijing 100094, China. Tel: 86-10-6237-3939. E-mail: yangxg@cau.edu.cn
}

Received: February 13, 2016 Accepted: April 21, 2016 Online Published: May 15, 2016

doi:10.5539/jas.v8n6p33 URL: http://dx.doi.org/10.5539/jas.v8n6p33

\begin{abstract}
Climate change has the potential to affect Chinese rice production; however, the rice crop could become more suitable to new climatic conditions because of benefits derived from new agricultural technologies. In this paper, a county-level dataset and crop model were used to analyze actual rice yield suitability by measuring the yield gap and yield stability from 1980 to 2011 in 1561 counties of China. The results showed that the national yield gap between the actual and potential yields was approximately $23.0 \%$, which is close to the threshold for profitable planting. However, a number of counties in the northeastern and southwestern regions showed a 30 to $50 \%$ yield gap, which indicates a relatively lower suitability of the rice. The rice yield stability results indicated that the actual stability has exceeded the potential stability in most of the counties of China, thus indicating a high level of suitability. Temporally, a decreasing trend was observed for both the yield gap and stability, suggesting that the suitability of rice in China has improved, which might be associated with the development of agricultural technology. The only noteworthy locations presenting a high yield gap and yield instability were several counties in the northeastern region. Since the northeastern region accounts for a significant proportion of China's rice production, further investigations should be conducted to identify the underlying causes of the yield gaps and determine methods of increasing the yield stability. The implementation of more suitable agricultural technology in the area is also suggested to improve the rice suitability in the region.
\end{abstract}

Keywords: climate change, crop suitability, rice, yield gap, yield stability

\section{Introduction}

In China, rice is one of the most important crops and accounts for approximately $35 \%$ of the total cereal crop production (FAOSTAT, 2013). Changes in the rice yield have the potential to significantly affect food security in China.

Climate change caused by rise in $\mathrm{CO}_{2}$ concentration has significantly alters the temperature and moisture regimes in China (Ding et al., 2006). A number of modeling studies have suggested that those changes have the potential to adversely influence Chinese rice growth (Yao, Xu, Lin, Yokozawa, \& Zhang, 2007; Chavas, Izaurralde, Thomson, \& Gao, 2009; Masutomi, Takahashi, Harasawa, \& Matsuoka, 2009). For example, climate change has been estimated to reduce the Chinese rice yield by 0.3 to $7 \%$ and increase the yield variability by 3 to 9\% (Yao et al., 2007). In addition, future rice yield projections indicate regional variability, with rice production in northeastern China predicted to benefit from $\mathrm{CO}_{2}$ fertilization effects and rice production in the east and south predicted to experience a declining trend in which harmful effect of warming is dominated (Masutomi et al., 2009).

Despite the negative potential consequences of climate change, several recent studies focusing on historical rice data found that growers appear to have successfully adapted to these negative climate effects by planting suitable rice cultivars (Liu, Wang, Zhu, \& Tang, 2012; Tao et al., 2013), rearranging rice production areas (Lin, 2005; Yang et al., 2007) and providing better water management (T. Zhang, Zhu, Yang, \& X. Zhang, 2008; Deng et al., 2010). Thus, possible negative outcomes have not been observed to a large extent. Accessibility to new agricultural technology and updated agricultural infrastructure have enabled Chinese rice to become more resilient to climate change and extreme weather shocks and more suitable to growing under new climate conditions (Fraser et al., 2008; Simelton, Graser, Termansen, Forster, \& Dougill, 2009). The progressively 
greater suitability of rice in the context of climate change is undoubtedly good news to Chinese rice production. However, to our knowledge, a national assessment of rice suitability under climate change has not yet been performed.

Evaluating the historical suitability of rice to climate change at a full national scale would provide new insights into how rice cultivation has adapted to past climate change, which could be used to determine whether the suitability of rice has improved in relation to climate change at a national scale and identify locations of vulnerable hotspots in need of further adaptations. These historical insights could inform our baseline capacity to adapt to climate change, which could be used as a guide for Chinese agricultural policymakers.

Conventional crop suitability assessments are generally based on yield gap analyses (Fischer, Velthuizen, Shah, \& Nachtergaele, 2002), which assess the actual yield relative to the potential yield to determine the suitability of the crop yield according to climatic factors. However, this analysis only considers the yield level and does not consider yield stability, another aspect of food security that is becoming increasingly recognized (Schmidhuber \& Tubiello, 2007). Low yield stability often results in unpredictable food shortages, which threaten food supplies and farmers' livelihoods (Schmidhuber \& Tubiello, 2007). However, the consequences of variations in crop yields have received little attention.

The objective of this study is to 1) provide a national assessment on historical rice yield suitability over the period from 1980 to 2011 by quantifying the actual yield and yield stability relative to their potential levels and 2) identify regional variability in yield and stability, which will be used to support rice production security under changing climatic conditions. This study uses a high resolution county-level rice yield dataset for China to simulate the potential yield for each county; therefore, this study provides a comprehensive evaluation of China's rice yield suitability on a national scale.

\section{Materials and Methods}

\subsection{Data sources and Preparation}

A rice yield dataset at the county level was collected from the Agricultural Information Center at the Chinese Agricultural Academy of Sciences. In this study, these data represent the actual rice yields of Chinese farmers, which cover 1561 counties (Figure 1a) in 28 provinces (Figure 1b). Climatic data were downloaded from the China Meteorological Data Sharing Service System (http://cdc.cma.gov.cn/). Climatic observations include daily minimum and maximum temperatures, sunshine hours, vapor pressure, wind speed and rainfall for the period from 1980 to 2011. Because the dataset only included 756 stations and did not satisfy the climate input requirement of the model for each county, we estimated the daily climate data using the algorithm presented by Thornton, Running, \& White (1997); this algorithm interpolates the abovementioned data of the 756 climate stations into $10 \mathrm{~km}$ grid cells and then extracts climatic information from the grid data that corresponds to the locations of the 1561 counties. 
(a)

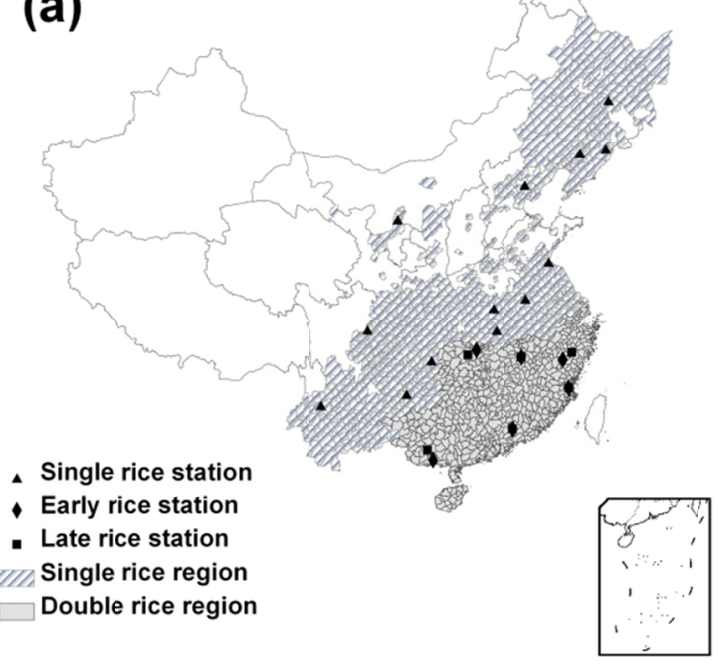

(b)

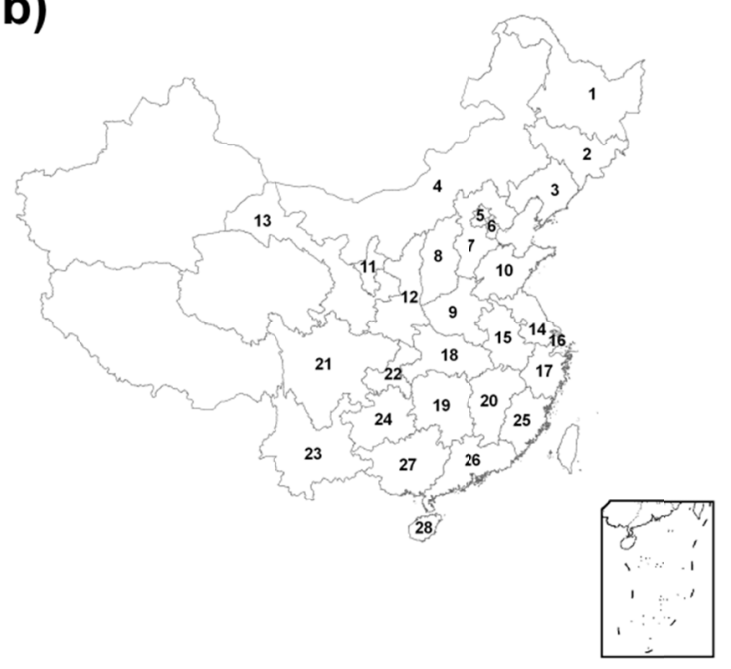

Figure 1. (a) The counties and experimental stations involved in this study; (b) The provinces involved in the study

Note. The ID numbers correspond to each province: 1-Heilongjiang, 2-Jilin, 3-Liaoning, 4-Inner Mongolia, 5-Beijing, 6-Tianjin, 7-Hebei, 8-Shanxi, 9-Henan, 10-Shandong, 11-Ningxia, 12-Shaanxi, 13-Gansu, 14-Jiangsu, 15-Anhui, 16-Shanghai, 17-Zhejiang, 18-Hubei, 19-Hunan, 20-Jiangxi, 21-Sichuan, 22-Chongqing, 23-Yunnan, 24-Guizhou, 25-Fujian, 26-Guangdong, 27-Guangxi, 28-Hainan.

Experimental rice data were collected from agro-meteorological experimental stations operated by the China Meteorological Administration. The dataset includes phenological dates (emergence, transplantation, panicle initiation, flowering and physiological maturity dates), yield and management data. These data were used to calibrate the crop model. The experimental rice stations include the ones planting rice one time in each year in single rice region and those planting early and late rice in double rice region (Figure 1).

\subsection{ORYZA2000 Model}

The ORYZA2000 rice model was developed to simulate the growth, development and water balance of lowland rice (Bouman et al., 2001), and it has been widely used for a range of applications across climatic and regional environments (Bouman \& van Laar, 2006; Li et al., 2013; Zhang, Yang, Wang, Li, \& Ye, 2014). Model calibration was performed by comparing the simulated values to the experimental rice data. In each province, we selected a representative cultivar for a specific cropping system (Table 1). The cultivars were selected based on data availability, and we intentionally chose cultivars used in experiments over multiple years so that sufficient data were available to calibrate and validate the crop model. The station locations are shown in Figure 1a. 
Table 1. Representative cultivars for experimental stations in the study

\begin{tabular}{|c|c|c|c|c|c|}
\hline Province & $\mathrm{ID}^{1}$ & Season & Cultivar & Calibration dataset & Validation dataset \\
\hline \multicolumn{6}{|l|}{ Northeast } \\
\hline Heilongjiang & 1 & Single & $93-8$ & Wuchang (2001-2003) & Wuchang (2004-2005) \\
\hline Jilin & 2 & Single & Qiuguang & Tonghua (1993-1997) & Tonghua (1998-2000) \\
\hline Liaoning & 3 & Single & Liaojing294 & Dengta $(1998,2000-2002)$ & Dengta (2003-2005) \\
\hline \multicolumn{6}{|l|}{ North } \\
\hline Hebei & 7 & Single & Kendao95-4 & Zunhua $(2000,2001)$ & Zunhua $(2002,2003)$ \\
\hline Henan & 9 & Single & TeSanErAi & Xinyang $(1993,1994)$ & Xinyang $(1995,1996)$ \\
\hline \multicolumn{6}{|l|}{ Northwest } \\
\hline Ningxia & 11 & Single & Ningjing29 & Yinchuan $(2002,2003)$ & Yinchuan $(2004,2005)$ \\
\hline \multicolumn{6}{|l|}{ East } \\
\hline Jiangsu & 14 & Single & Zaofeng6 & Xuzhou (2001-2004) & Ganyu (1999) \\
\hline Anhui & 15 & Single & Xieyou63 & Shouxian $(2000,2002)$ & Shouxian $(2003,2005)$ \\
\hline Zhejiang & 17 & Early & Zhe733 & Jinhua (1996-1999) & $\begin{array}{l}\text { Lishui }(1994,1995,1999), \\
\text { Lonogquan }(1994,1996,1997,2002)\end{array}$ \\
\hline Zhejiang & 17 & Late & 2You92 & Lishui $(1996,2000,2001)$ & Longquan (2001), Lishui (2002) \\
\hline \multicolumn{6}{|l|}{ Central } \\
\hline Hubei & 18 & Single & Shanyou63 & Wuhan (1994-1999) & Yunxi (1998-2001) \\
\hline Hunan & 19 & Early & Zhefu7 & Changde $(1997,1999)$ & Nanxian (1997) Changde (2003) \\
\hline Hunan & 19 & Late & Weiyou64 & $\begin{array}{l}\text { Changde (1986), } \\
\text { Wugang (1987-1990) }\end{array}$ & Wugang (1991-1993), Pingjiang (2001) \\
\hline Jiangxi & 20 & Early & Ganzaoxian14 & Nanchang $(1991,1992)$ & Nanchang (1993) \\
\hline Jiangxi & 20 & Late & Zhongyougui99 & Nanchang (2002) & Nanchang (2003) \\
\hline \multicolumn{6}{|l|}{ Southwest } \\
\hline Sichuan & 21 & Single & DYou63 & Leshan $(1988,1992-2001)$ & Bazhong (1994), Dujiangyan (1993-1996) \\
\hline Chongqing & 22 & Single & Eryou & Youyang $(1997,1998,2000)$ & Youyang (2001-2003) \\
\hline Yunnan & 23 & Single & Dianza31 & Dali $(2003,2005,2006)$ & Dali $(2007,2009)$ \\
\hline Guizhou & 24 & Single & Jinyou63 & Guiyang $(2001,2003)$ & Guiyang (2005) \\
\hline \multicolumn{6}{|l|}{ South } \\
\hline Fujian & 25 & Early & Jiayu164 & Fuzhou (2004-2006) & Fuzhou (2007-2009) \\
\hline Fujian & 25 & Late & Yixiang2292 & Fuzhou (2006) & Fuzhou (2008) \\
\hline Guangdong & 26 & Early & SanErAi & Heyuan (1987-1990) & Heyuan (1991-1994) \\
\hline Guangdong & 26 & Late & GuangEr104 & Heyuan (1985-1988) & Heyuan (1989-1992) \\
\hline Guangxi & 27 & Early & Teyou63 & Nanning (2002-2009) & Yulin (1999, 2000), Qinzhou (1996) \\
\hline Guangxi & 27 & Late & Boyou903 & Nanning (1994-1997) & Nanning (2000-2004) \\
\hline
\end{tabular}

Note. ${ }^{1}$ The ID number corresponds to Figure $1 \mathrm{~b}$.

In this study, the ORYZA2000 model was used as a tool to evaluate potential yields under optimum supplies of water and nitrogen, and these yield values were used to represent yield changes exclusively caused by climatic conditions. Other management information (i.e., emergence dates, seed-bed duration and planting density) was assumed to be province-specific and set to the average value of the experimental rice data. Crop coefficients were derived from the representative rice cultivars and assumed to be province-specific. For certain provinces in the northwest, we lacked experimental rice data; in these cases, the cultivar coefficients from nearby provinces 
that share a similar cropping system were used. Moreover, because the county-level yield dataset did not provide separate yields for the early and late rice seasons, the simulated early and late rice yield potentials were averaged and weighted by the sowing areas for early and late rice according to provincial level data from a statistics yearbook and from the National Bureau of Statistics of China website (http://www.stats.gov.cn/tjsj/ndsj/). We assumed that the province-specific percentages of early and late season rice were consistent between years for all counties in the province, and the yield values for each county-year combination were estimated by multiplying the area-weighted percentage for the simulated early and late rice yields. Although clearly not ideal, such practices allowed us to determine a first-order approximation of the yield potential for all of China that could be compared with the available county yield data.

\subsection{Index of the Yield Gap and Variation Differences}

To achieve the objectives of this study, two indices were used to quantify the actual rice yield suitability in relation to climate change: a yield gap index and yield variation difference index. All of the statistical analyses were executed in R version 3.02 ( $\mathrm{R}$ Core Team 2013).

Yield gap. The yield gap was defined as the percentage difference between the potential and actual yield (Equation 1), and the index was used to quantify the similarity between the actual yields and their potential levels in each county. A lower value of the index indicates that the actual yield is closer to its potential level and more suitable for the climatic conditions.

$$
Y G=\frac{Y_{p}-Y_{a}}{Y_{p}} \times 100 \%
$$

Where, $Y G$ denotes the yield gap (\%) and $Y_{p}$ and $Y_{a}$ denote the potential and actual yield, respectively.

Yield variation difference. As mentioned in the introduction section, yield stability is another important index for crop suitability. In this study, we adopted the yield variation index used by Reilly et al. (2003) to quantify the yield stability (Equation 2).

$$
V=\left|\frac{Y_{t}-Y_{\text {trend }}}{Y_{\text {trend }}}\right| \times 100 \%
$$

Where, $V$ is the yield variation difference (\%), $Y_{t}$ is the rice yield in year $\mathrm{t}\left(\right.$ ton ha $\left.{ }^{-1}\right)$ and $Y_{\text {trend }}$ is the fitted yield in each series, which is determined using a smoothing spline method and indicates the yield trend over time (ton $\mathrm{ha}^{-1}$ ).

The yield gap was similarly defined by quantifying the suitability of the rice cultivar relative to the yield stability by determining the difference between the actual and potential yields (Equation 3).

$$
V D=V_{a}-V_{p}
$$

Where, $V D$ is the yield variation difference (\%), $V_{a}$ is the yield variation calculated from the observed county yield data, and $V_{p}$ is the yield variation calculated from the simulated potential yield data.

\section{Results}

\subsection{ORYZA2000 Calibration and Evaluation}

The ORYZA2000 model was calibrated based on the observations on day after emergence (DAE) of flowering and maturity dates and rice yields. Based on Figure 2 and Table 2, there is a good agreement between the simulated and observed yields and phenology for both the calibration and validation datasets. The normalized root-mean-square error (NRMSE) for the yield simulation was approximately 13\%, and the NRMSE for phenology varied from $3.7-5.1 \%$ (Table 2 ). 

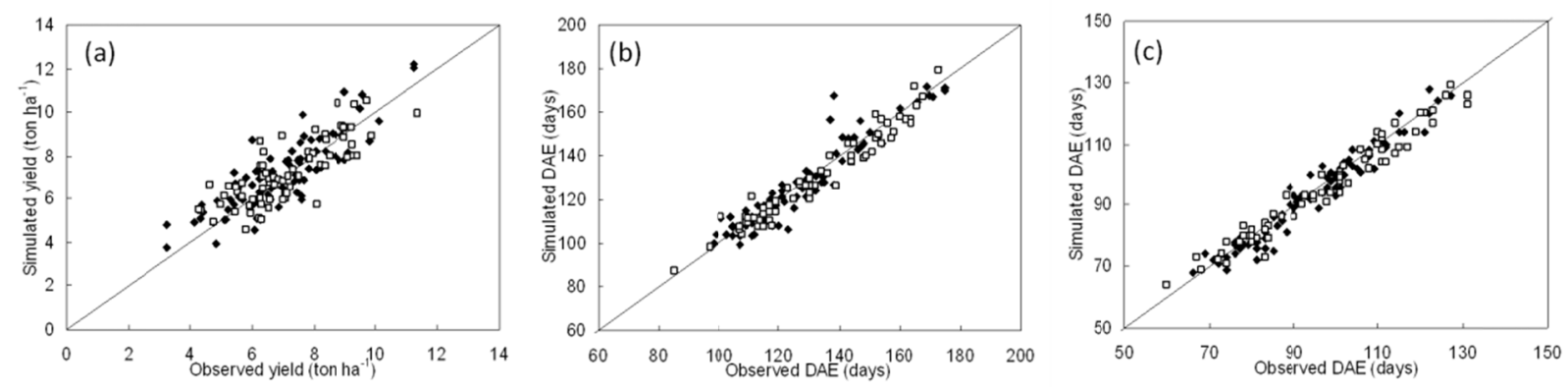

Figure 2. Model fitness for yield (a), flowering DAE (b) and maturity DAE (c)

Note. The $\bullet$ denotes the calibration data, and the $\square$ denotes the validation data.

Table 2. Evaluation of the ORYZA2000 model performance for yield, day after emergence (DAE) of flowering and maturity

\begin{tabular}{|c|c|c|c|c|c|}
\hline Variable & $\mathbf{n}$ & Average (OBS) & Average (SIM) & $\mathbf{R}^{2}$ & NRMSE \\
\hline \multicolumn{6}{|l|}{ Calibration } \\
\hline Yield (ton ha ${ }^{-1}$ ) & 85 & 7.00 & 7.20 & 0.74 & $13.2 \%$ \\
\hline DAE Flowering (days) & 85 & 94 & 93 & 0.97 & $3.7 \%$ \\
\hline DAE Maturity (days) & 85 & 129 & 128 & 0.89 & $5.1 \%$ \\
\hline \multicolumn{6}{|l|}{ Validation } \\
\hline Yield (ton ha ${ }^{-1}$ ) & 69 & 7.20 & 7.30 & 0.63 & $13.5 \%$ \\
\hline DAE Flowering (days) & 69 & 97 & 94 & 0.95 & $4.3 \%$ \\
\hline DAE Maturity (days) & 69 & 132 & 130 & 0.94 & $4.1 \%$ \\
\hline
\end{tabular}

After obtaining the crop coefficients, we applied them for each county, and the yields were simulated under potential growing conditions to obtain the potential yields at the regional scale. A detailed model configuration of the representative cultivar coefficients and other management settings is included in Appendix A.

\subsection{Yield Gap and Variation Differences}

The mean yield potential from 1980 to 2011 on a national scale was approximately 7.9 ton ha $^{-1}$, and the spatial distribution is shown in Figure 3a. According to these results, relatively higher potential yield values (8-10 ton $\mathrm{ha}^{-1}$ ) were observed for the majority of counties in the northeastern, northwestern and southwestern regions, whereas the regions with lower potential yields (less than 7 ton ha ${ }^{-1}$ ) included a number of counties in the southern and eastern regions. However, the national mean actual yields from 1980 to 2011 were generally lower (5.9 ton $\mathrm{ha}^{-1}$ ) than their potential levels and exhibited a different spatial pattern (Figure 3b). Higher yield regions were also observed in the eastern, southwest and northwest regions as well as certain lower portions of the northeastern region, although this result was not simulated by the model (Figure 3a), with values varying between 7 and 8 ton ha ${ }^{-1}$. The average actual yields were generally lower in the southern regions $\left(\leq 7\right.$ ton $\left.\mathrm{ha}^{-1}\right)$. The yield gap average was approximately $23 \%$ at the national level and showed a strong spatial distribution. Lower yield gap regions were observed in the eastern region (Anhui, Jiangsu and Zhejiang provinces), central region (Hunan and Jiangxi provinces), and southern region (Guangdong and Guangxi provinces) and some counties in the southwestern region (Sichuan Province), whereas counties in the northeast region (Liaoning, Jilin and Heilongjiang provinces) and the lower portion of the southwestern region (Yunnan Province) exhibited higher yield gap values (Figure 3c). 

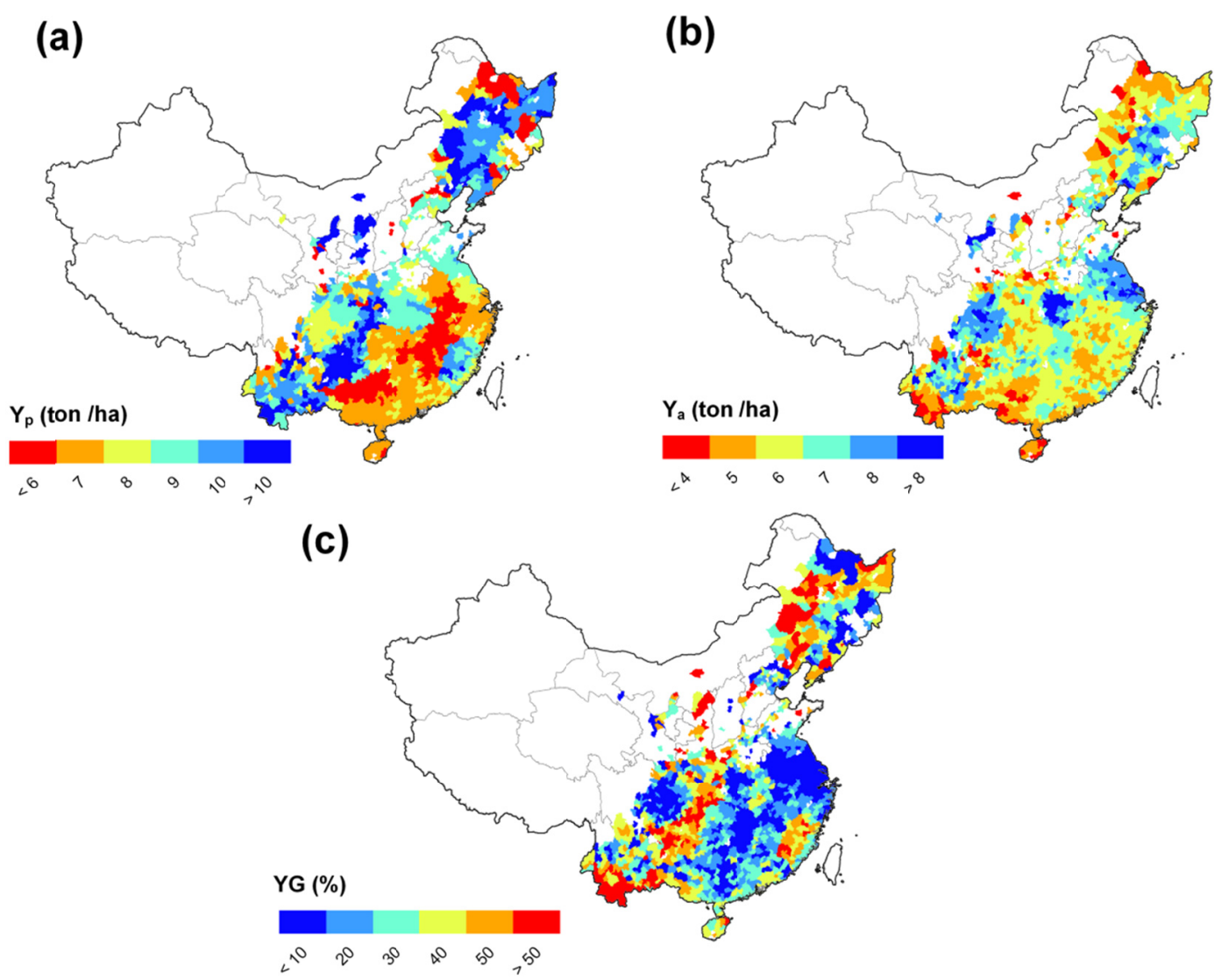

Figure 3. Averages for the potential yield (a), actual yield (b) and yield gap (c)

The yield variance demonstrated a clear spatial distribution (Figure 4). Under the potential growing conditions, the regions with higher variations were located in the upper parts of the northeastern region (Heilongjiang Province) and portions of the southwestern region (Yunnan Province), with values varying between 16 and 20\%, whereas the yields presented greater stability in the remaining regions $(\leq 12 \%)$ as shown in Figure $4 \mathrm{a}$. The spatial distribution of the actual yield variation was consistent with the simulated model except that the higher potential yield variations simulated for the southwest region were not observed with the actual yields (Figure $4 \mathrm{~b}$ ). However, the actual yield variation $(5.7 \%)$ was already lower than the potential yield variation $(8.5 \%)$ at the national level as reflected by the overall negative differences in variation observed in most areas (Figure 4c). 
(a)

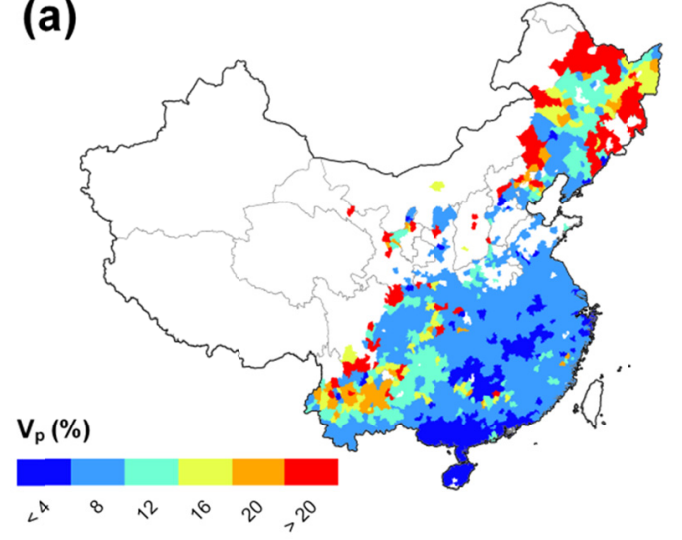

(b)

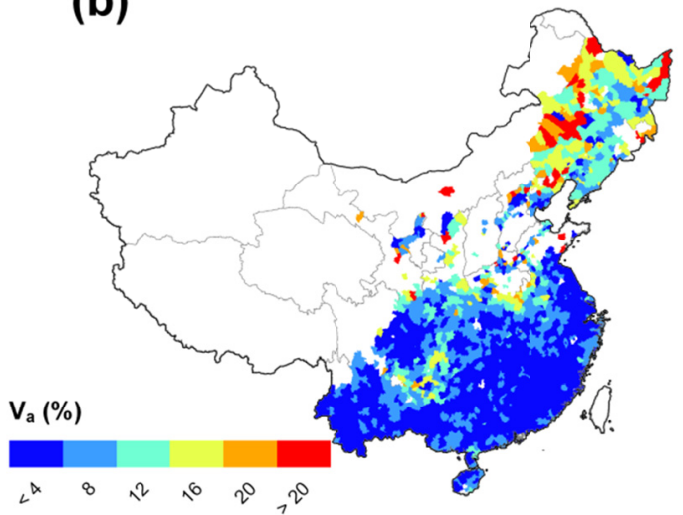

(c)

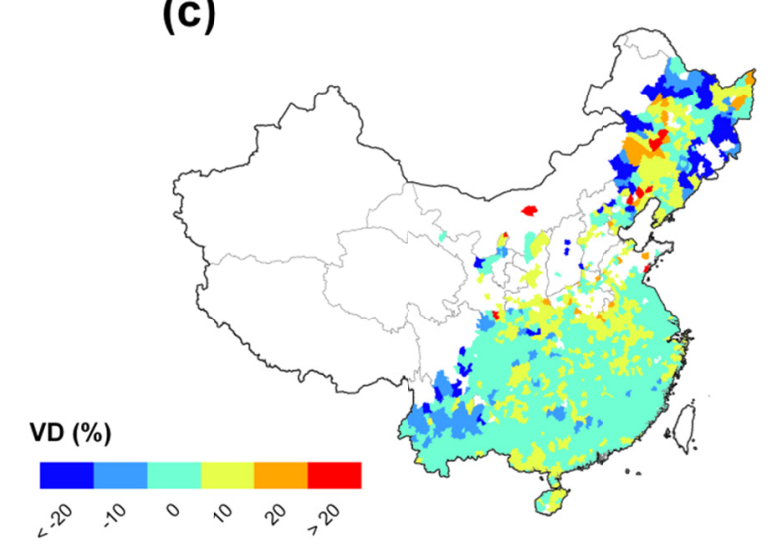

Figure 4. Averages for the potential yield variance (a), actual yield variance (b) and yield variance difference (c)

\subsection{Time Trends in the Yield Gap and Variation Differences}

A downward trend was observed for the potential yield during the period from 1980 to 2011 across the majority of China except for in the upper portions of the northeastern region (Heilongjiang Province and parts of Inner Mongolia) and certain counties in the southwestern region (Yunnan Province), which showed an increasing trend for potential yield (Figure 5a). The actual yields generally increased from 1980 to 2011 in most areas, with the northeastern region (Heilongjiang, Jilin and Liaoning provinces) exhibiting the most rapidly improved yield (more than 1.0 ton $\mathrm{ha}^{-1}$ decade $^{-1}$ ) as shown in Figure $5 \mathrm{~b}$. Thus, most regions exhibited a uniform but narrow yield gap over time, averaging 11.7 ton $\mathrm{ha}^{-1}$ decade $^{-1}$ (Figure 5c). 


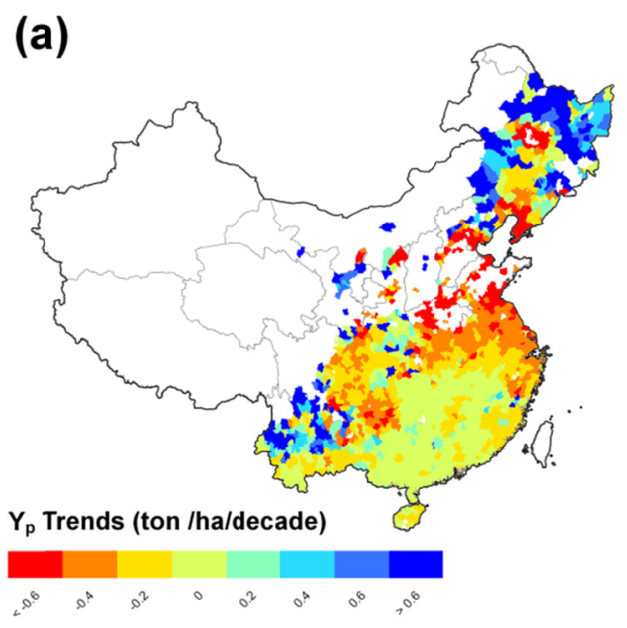

(b)

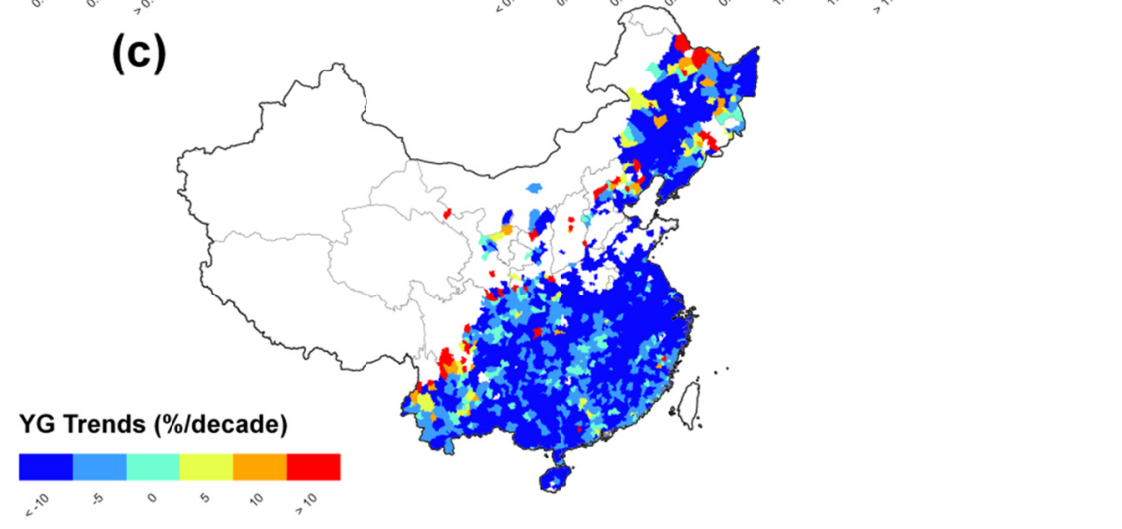

Figure 5. Time trends for the potential yield (a), actual yield (b) and yield gap (c)

The spatial distribution of the potential yield variations varied and was unclear, with increasing and decreasing trend regions intertwined together (Figure 6a). However, the actual yield variation showed a consistently decreasing trend in the majority of the counties in our study area (Figure 6b), with a rapidly decreasing trend observed in the northeast region $\left(-5.0-0 \%\right.$ decade $\left.^{-1}\right)$ and a slightly slower reduction in the southern region $\left(-2.5-0 \%\right.$ decade $\left.^{-1}\right)$. Because of the decreasing trend in the actual yield variations, the differences in yield variation were also reduced over time in most of the counties, with several counties in the northeast and southwest regions showing an increasing trend (Figure 6c). 
(a)

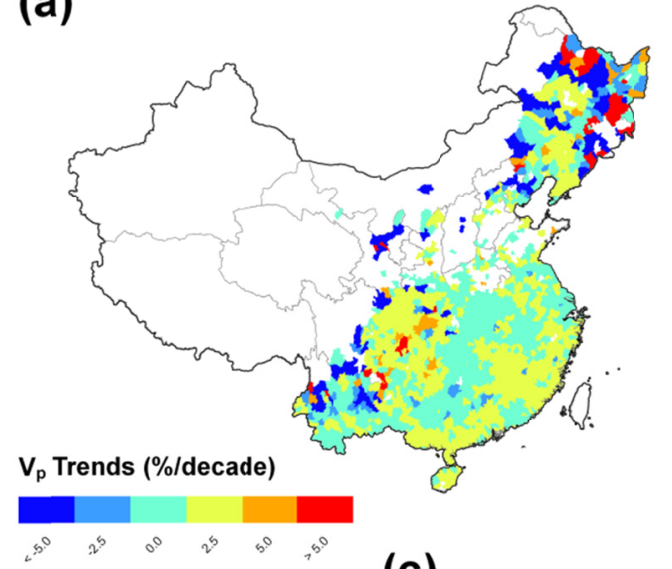

(b)

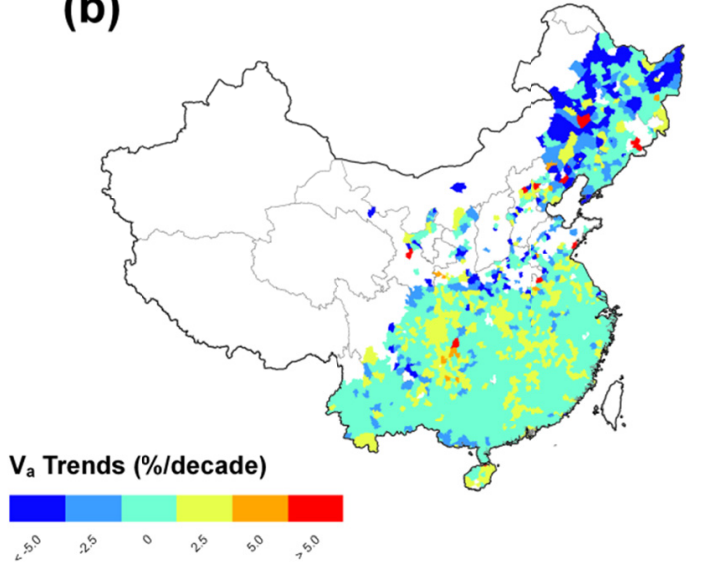

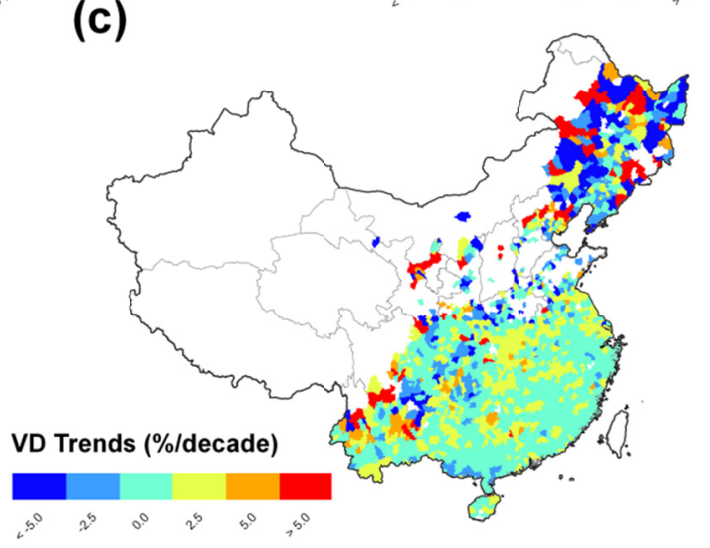

Figure 6. Time trends for the potential yield variance (a), actual yield variance (b) and yield variance difference (c)

\subsection{Rice Suitability to Climate}

Figure 7 presents a combination of the yield gap and the yield variation difference indices, which were used to map the actual rice yield suitability over the study period. Based on the above results, we followed the previous classifications used to assess yield gaps. We also separated the yield variation difference index into two levels: greater than zero and less than zero. Values greater than zero (shown by more opaque color) indicated that the actual yields presented greater fluctuations compared with their potential values and less suitable in the yield changes, whereas values less than zero (shown by the more transparent color) indicated that the actual yields were more stable compared with their potential values.

The locations that exhibited higher yield gaps and higher yield variation differences were located in the western portion of the northeastern region (Inner Mongolia) and certain counties in the southwest region (Yunnan and Sichuan provinces) (Figure 7a). Temporally, the majority of counties showed a progressive decreasing trend for the yield gap and lower yield variations (Figure 7b). 
(a)

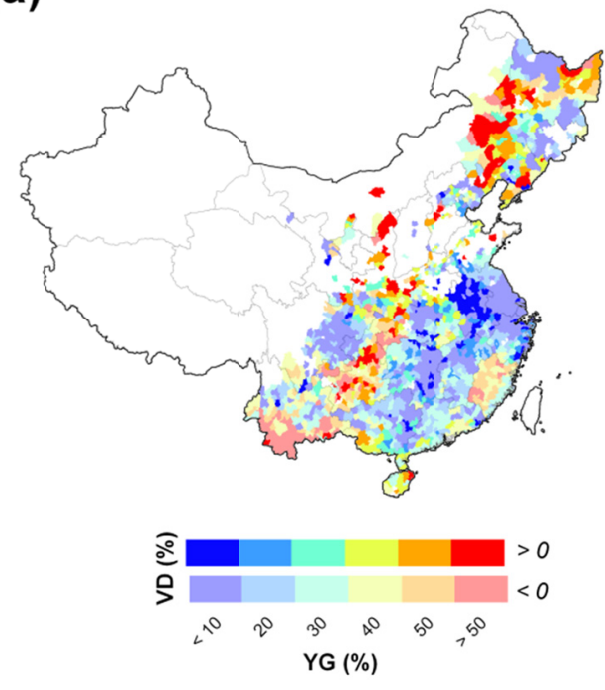

(b)

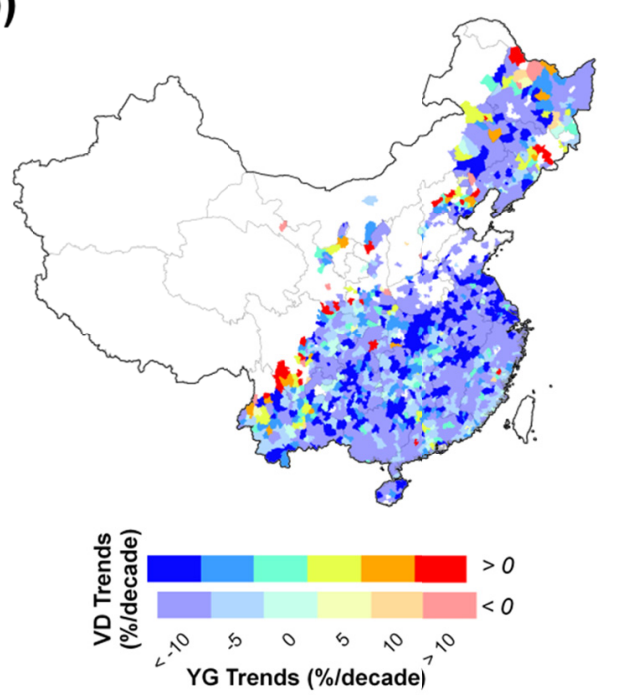

Figure 7. Crop suitability as measured by the yield gap index and yield variation difference index

\section{Discussion}

This paper aimed to identify the status of and changes to the actual yield suitability for Chinese rice from 1980 to 2011. The yield suitability was measured by two indices: the yield gap index and the yield variation differences index. The yield gap index was frequently used as an indicator in earlier suitability assessments (Fischer et al., 2002), whereas the yield variation differences index indicates the stability of the yield, which is another equally important aspect for food security (Schmidhuber \& Tubiello, 2007) and can be used to compensate for the yield gap and provide a more comprehensive evaluation of crop suitability.

We firstly calibrated the ORYZA2000 model and found there is a good agreement between simulated and observed yields and phenologies. The evaluation indices are consistent with the results of other studies (Timsina \& Humphreys, 2006; Belder, Bouman, Spiertzm, \& Lu, 2007), thus indicating that the ORYZA2000 model produces a satisfactory simulation for the yields and the phenology dates of the representative cultivars.

Based on the potential yields estimated by the model and the county-level yield data for 1561 counties, our results indicated that the average rice yield gap at the national level was $23 \%$, a value that is consistent with earlier assessments for rice yield gaps in China that applied different approaches. For example, the experimental station evidence indicates a $25 \%$ rice yield gap (Dat, 2001); the farmers' attainable yield record suggests a 17 to $27 \%$ rice yield gap (Zhu, 2000); and a statistical approach determined an approximately $20 \%$ rice yield gap (Mueller et al., 2012). The above comparisons suggest that the methods applied here produced comparable and robust measurements of the rice yield gap in China.

The rice yield gap decreased in most of the regions of China from 1980 to 2011 (Figure 5), which indicates greater suitability of the actual rice yield to its climatic potential level in terms of yield gap. This result is attributed to the introduction of certain high-yield management practices, such as hybrid rice breeding technology (Peng, Tang, \& Zou, 2009; Liu et al., 2012). The reduction of potential yields in most regions (Figure 5a) was associated with the warming climate (Zhang et al., 2014), and despite the decreasing trend, a large yield gap (30-50\%) was observed in a number of counties in the northeastern and southwestern regions (Figure 3c). Because a value of $20 \%$ is frequently used as a threshold yield gap value at a regional scale as proposed by Cassman (1999), large yield improvements may still occur for the northeastern and southwestern regions. The large yield gap in the northeast was caused by the beneficial effects of climate changes (Yang et al., 2007), which enabled greater potential yields (Figure 3a) relative to the actual yields (Figure 3b), whereas the large yield gap in the southwest was caused by intense radiation resources (Katsura et al., 2008; Zhang et al., 2014) that have not yet been fully utilized (Figure 3a). Further investments in advanced agricultural practices, breeding technologies and high efficiency agricultural management should be considered to increase these local yields and improve their suitability for their specific climate conditions.

In addition to the yield gap, our results also emphasized the stability of the yield. We observed a clear spatial 
distribution in stability, with the rice yield in the northern region more variable than that in the southern region for both the potential (Figure $4 \mathrm{a}$ ) and actual yields (Figure $4 \mathrm{~b}$ ) averaged over the study period. One of the reasons for the observed variability may be the longer growing season in the north, which causes a greater potential for variability under adverse climatic conditions. However, the actual yield variation was generally lower than the potential yield variation, which caused a uniform negative yield variation difference except in certain counties in the northeast (Figure 4c). The negative values indicate that the actual rice yield has already become more stable than the values derived under potential climate change conditions. Higher yield variability under potential conditions is not uncommon and has been observed in American (Hansan \& Jones, 2000) and European maize (Reidsma, Ewert, Boogaard, \& Diepen, 2009). In our region, the local adaptive responses to adverse climatic impacts not accounted for in the crop model may further reduce the influence of climatic factors and promote even lower observed yield variability. Such inconsistency between the potential and actual yield variations was also observed temporally (Figure 6). Compared with the spatial distribution for the potential yield variance trends (Figure 6a), the actual yield variance trends exhibited a uniform decreasing trend over time in most counties (Figure 6b). The more stable trend of the actual yield was consistent with several earlier empirical studies (Simelton, Graser, Termansen, Forster, \& Dougill, 2009; Zhang et al., 2008), which attributed this trend to progressive improvements in several socio-economic factors in China, including technical inputs, breeding investments and mechanization. As a result, the yield variation differences also experienced a downward trend, indicating improved rice suitability because of the current agricultural technological developments in China. Therefore, our results suggest a positive outcome for yield stability because Chinese rice cultivars were able to maintain a stable yield according to average values and temporal trends.

By combining the yield gap index and variation difference index, this study mapped the actual yield suitability from 1980 to 2011 (Figure 7). Over most of the study area, the actual rice yields exhibited a high level of suitability in relation to the local climate. On average, the actual yields over the study period were close to the potential values and exhibited a high level of stability (Figure 7a), especially for the eastern and southern regions, which are the traditional rice production regions in China. Temporally, the yield gap between the actual and potential rice yields was reduced and became more stable over the majority of the study regions (Figure 7b). At a national level, several large yield gaps in the northeast and southwest regions should be given a higher priority and investigated in further studies because the actual rice yield has performed well in terms of stability, and the yield gaps have the potential to decrease. Finally, the only locations that showed a high yield gap and high variance differences were located in the northeast and northwest regions. Because of recent increases in the rice planting areas (Lin, 2005; Yang et al., 2007) and the greater production demands on the northeastern region to meet China's food self-sufficiency (Simelton, 2011), further investigations are recommended to maintain yield improvements and ensure yield stability in the northeastern region of China.

\section{Conclusions}

In order to understand how yield suitability changes in China, we investigated rice yield gap and stability over 1980 to 2011 in 1561 counties of China. The level and variance of yields relative to their potential ones indicates whether the historical climate change and technology improvement has made the yield more suitable for their growing environments or not. Potential yield changes due to climate were calculated by crop model, which compared with actual yield statistics. Results suggest that the national yield gap between the actual and potential yields was approximately $23.0 \%$. However, this presents a regional heterogeneity; a number of counties in the northeastern and southwestern regions showed a 30 to $50 \%$ yield gap, which indicates a relatively lower suitability of the rice. On the other hands, actual rice yield stability has exceeded the potential stability in most of the counties of China, thus indicating a high level of suitability. There is a decreasing trend for both yield gap and stability, indicating that the suitability of rice in China has improved, which might be associated with the development of agricultural technology. The only locations showing a high yield gap and yield instability were several counties in the northeastern region. Therefore, we conclude that the region of northeastern in China has a potential to improve the level and stability of yields. Given the northeastern region accounts for a significant proportion of China's rice production, further investigations should be conducted to identify the underlying causes of the yield gaps and determine methods of increasing the yield stability.

\section{Acknowledgements}

This work was supported by the Meteorology-Scientific Research in the Public Interest (GYHY201106020), and the National Natural Science Foundation of China (41661144006; 41301044; 41321064).

\section{References}

Belder, P., Bouman, B. A. M., Spiertzm, J. H. J., \& Lu, G. (2007). Exploring options for water savings in 
lowland rice using a modeling approach. Agricultural Systems, 92, 91-114. http://dx.doi.org/10.1016/j.ags y.2006.03.001

Bouman, B. A. M., \& van Laar, H. H. (2006). Description and evaluation of the rice growth model ORYZA2000 under nitrogen-limited conditions. Agricultural Systems, 87, 249-273. http://dx.doi.org/10.1016/j.agsy.2 004.09.011

Bouman, B. A. M., Kropff, M. J., Tuong, T. P., Wopereis, M. C. S., ten Berge, H. F. M., \& van Laar, H. H. (2001). ORYZA2000: Modeling Lowland Rice. International Rice Research Institute, Los Baños, Philippines/Wageningen University and Research Centre, Wageningen, The Netherlands

Cassman, K. G. (1999). Ecological intensification of cereal production systems: Yield potential, soil quality, and precision agriculture. Proceedings of the National Academy of Sciences of the United States, 96, 5952-5959. http://dx.doi.org/10.1073/pnas.96.11.5952

Chavas, D. R., Izaurralde, R. C., Thomson, A. M., \& Gao, X. (2009). Long-term climate change impacts on agricultural productivity in eastern China. Agricultural and Forest Meteorology, 149, 1118-1128. http://dx.doi.org/10.1016/j.agrformet.2009.02.001

Dat, V. T. (2001). Closing the rice yield gap for food security. In J. Chataigner (Eds.), The New Development in Rice Agronomy and its Effects on Yield and Quality in Mediterranean Areas (pp. 1-12). Montpellier: CIHEAM.

Deng, X., Huang, J., Qiao, F., Naylor, R. L., Falcon, W. P., Burke, M., ... Battisti, D. (2010). Impacts of El Nino-Southern oscillation events on China's rice production, Journal of Geographical Sciences, 20, 3-16. http://dx.doi.org/ 10.1007/s11442-010-0003-6

Ding, Y., Ren, G., Shi, G., Gong, P., Zheng, X., Zhai, P., ... Dai, X. (2006). National assessment report of climate change (I): Climate change in China and its future trend. Advances in Climate Change Research, 2, 3-8.

FAOSTAT. (2013). Retrieved from http://faostat3.fao.org/home/index.html

Fischer, G., van Velthuizen, H., Shah, M., \& Nachtergaele, F. (2002). Global agro-ecological assessment for agriculture in the 21st century: Methodology and results. Food and Agriculture Orgnazation of the United Nations, Rome, Italy.

Fraser, E. D. G., Termansen, M., Sun, N., Guan, D., Simelton, E., Dodds, P., ... Yu, Y. (2008). Quantifying socioeconomic characteristics of drought-sensitive regions: Evidence from Chinese provincial agricultural data. Comptes Rendus Geoscience, 340, 679-688. http://dx.doi.org/10.1016/j.crte.2008.07.004

Hansen, J. W., \& Jones, J. W. (2000). Scaling-up crop models for climate variability applications. Agricultural Systems, 65, 43-72. http://dx.doi.org/10.1016/S0308-521X(00)00025-1

Katsura, K., Maeda, S., Lubis, I., Horie, T., Cao, W., \& Shiraiwa, T. (2008). The high yield of irrigated rice in Yunnan, China: A cross-location analysis. Field Crops Research, 107, 1-11. http://dx.doi.org/10.1016/j.f cr.2007.12.007

Li, T., Raman, A. K., Marcaida III, M., Kumar, A., Angleles, O., \& Radanielson, A. M. (2013). Simulation of genotype performances across a large number of environments for rice breeding using ORYZA2000. Field Crops Research, 149, 312-321. http://dx.doi.org/10.1016/j.fcr.2013.05.006

Lin, E. (2005). Case study 1: China benefiting from global warming: agricultural production in Northeast China. IDS Bulletin, 36, 15-32. http://dx.doi.org/10.1111/j.1759-5436.2005.tb00232.x

Liu, L., Wang, E., Zhu, Y., \& Tang, L. (2012). Contrasting effects of warming and autonomous breeding on single-rice productivity in China. Agricultural, Ecosystems \& Environment, 149, 20-29. http://dx.doi.org/10.1016/j.agee.2011.12.008

Masutomi, Y., Takahashi, K., Harasawa, H., \& Matsuoka, Y. (2009). Impact assessment of climate change on rice production in Asia in comprehensive consideration of process/parameter uncertainty in general circulation model. Agricultural, Ecosystems \& Environment, 131, 281-291. http://dx.doi.org/10.1016/j. agee.2009.02.004

Mueller, N. D., Gerber, J. S., Johnston, M., Ray, D. K., Ramankutty, N., \& Foley, J. A. (2012). Closing yield gaps through nutrient and water management. Nature, 490, 254-257. http://dx.doi.org/ 10.1038/nature11420

Peng, S., Tang, Q., \& Zou, Y. (2009). Current status and challenges of rice production in China. Plant Production Science, 12, 3-8. http://dx.doi.org/10.1626/pps.12.3 
R Development Core Team. (2013). $R$ : A language and environment for statistical computing, $R$ Foundation for Statistical Computing: Vienna, Austria. ISBN 3-900051-07-0. Retrieved from http://www.R-project.org

Reidsma, P., Ewert, F., Boogaard, H., \& van Diepen, K. (2009). Regional crop modeling in Europe: The impact of climatic conditions and farm characteristics on maize yields. Agricultural Systems, 100, 51-60. http://dx.doi.org/10.1016/j.agsy.2008.12.009

Reilly, J., Tubiello, F., McCarl, B., Abler, D., Darwin, R., Fuglie, K., ... Rosenzweig, C. (2003). US agriculture and climate change: New results. Climatic Change, 57, 43-69. http://dx.doi.org/10.1023/A:1022103315424

Schmidhuber, J., \& Tubiello, F. N. (2007). Global food security under climate change. Proceedings of the National Academy of Sciences of the United States, 104, 19703-19708. http://dx.doi.org/10.1073/pnas. 0701976104

Simelton, E. (2011). Food self-sufficiency and natural hazard in China. Food Security, 3, 35-52. http://dx.doi.org/ 10.1007/s12571-011-0114-7

Simelton, E., Graser, E., Termansen, M., Forster, P., \& Dougill, A. (2009). Typologies of crop-drought vulnerability: An empirical analysis of the socio-economic factors that influence the sensitivity and resilience to drought of three major food crops in China (1961-2001). Environmental Science \& Policy, 12, 438-452. http://dx.doi.org/10.1016/j.envsci.2008.11.005

Tao, F., Zhang, Z., Shi, W., Liu, Y., Xiao, D., Zhang, S., ... Liu, F. (2013). Single rice growth period was prolonged by cultivars shifts, but yield was damaged by climate change during 1981-2009 in China, and late rice was just opposite. Global Change Biology, 19, 3200-3209. http://dx.doi.org/ 10.1111/gcb.12250

Thornton, P. E., Running, S. W., \& White, M. A. (1997). Generating surfaces of daily meteorological variables over large regions of complex terrain. Journal of Hydrology, 190, 214-251. http://dx.doi.org/10.1016/S0022-1694(96)03128-9

Timsina, J., \& Humphreys, E. (2006). Performance of CERES-Rice and CERES-Wheat models in rice-wheat systems: a review. Agricultural Systems, 90, 5-31. http://dx.doi.org/10.1016/j.agsy.2005.11.007

Yang, X., Lin, E., Ma, S., Ju, H., Guo, L., Xiong, W., ... Xu, Y. (2007). Adaptation of agriculture to warming in Northeast China. Climatic Change, 84, 45-58. http://dx.doi.org/ 10.1007/s10584-007-9265-0

Yao, F., Xu, Y., Lin, E., Yokozawa, M., \& Zhang, J. (2007). Assessing the impacts of climate change on rice yields in the main rice areas of China. Climatic Change, 80, 3-4. http://dx.doi.org/10.1007/s10584-006-9122-6

Zhang, T., Yang, X., Wang, H., Li, Y., \& Ye, Q. (2014). Climatic and technological ceilings for Chinese rice stagnation based on yield gaps and yield trend pattern analysis. Global Change Biology, 20, 1289-1298. http://dx.doi.org/ 10.1111/gcb.12428

Zhang, T., Zhu, J., Yang, X., \& Zhang, X. (2008). Correlation changes between rice yields in North and Northwest China and ENSO from 1960 to 2004. Agricultural and Forest Meteorology, 148, 1021-1033. http://dx.doi.org/10.1016/j.agrformet.2008.01.018

Zhu, D. (2000). Bridging the rice yield gap in China. In M. K. Papademetriou, F. J. Dent, \& E. M. Herath (Eds.), Bridging the Rice Yield Gap in the Asia-Pacific Region (pp. 69-83). Bangkok, Thailand, FAO. 


\section{Appendix}

\section{Appendix A}

Model configuration in each province in our simulation

\begin{tabular}{|c|c|c|c|c|c|}
\hline Province & Cropping Season & Cultivar & $\begin{array}{l}\text { Emergence } \\
\text { Julia day }\end{array}$ & $\begin{array}{l}\text { Seed-bed duration } \\
\text { Day length }\end{array}$ & $\begin{array}{l}\text { Planting density } \\
\text { Plant } \mathrm{m}^{-2}\end{array}$ \\
\hline \multicolumn{6}{|l|}{ Northeast } \\
\hline Heilongjiang & Single & $93-8$ & 124 & 22 & 90 \\
\hline Jilin & Single & Qiuguang & 116 & 29 & 90 \\
\hline Inner Mongolia & Single & Qiuguang & 116 & 29 & 90 \\
\hline Liaoning & Single & Liaojin294 & 112 & 35 & 90 \\
\hline \multicolumn{6}{|l|}{ North } \\
\hline Beijing & Single & Kendao95-4 & 121 & 39 & 136 \\
\hline Tianjin & Single & Kendao95-4 & 121 & 39 & 136 \\
\hline Hebei & Single & Kendao95-4 & 121 & 39 & 136 \\
\hline Shanxi & Single & Kendao95-4 & 121 & 39 & 136 \\
\hline Henan & Single & TeSanErAi & 124 & 34 & 120 \\
\hline Shandong & Single & TeSanErAi & 124 & 34 & 120 \\
\hline \multicolumn{6}{|l|}{ Northwest } \\
\hline Ningxia & Single & Ningjing29 & 116 & 19 & 120 \\
\hline Gansu & Single & Ningjing29 & 116 & 19 & 120 \\
\hline Shaanxi & Single & Ningjing29 & 116 & 19 & 120 \\
\hline \multicolumn{6}{|l|}{ East } \\
\hline Jiangsu & Single & Zaofeng8 & 134 & 35 & 120 \\
\hline Anhui & Single & Xieyou63 & 131 & 30 & 120 \\
\hline Shanghai & Single & Zaofeng8 & 134 & 35 & 120 \\
\hline Zhejiang & Early & Zhe733 & 98 & 26 & 120 \\
\hline Zhejiang & Late & 2 you92 & 175 & 33 & 120 \\
\hline \multicolumn{6}{|l|}{ Central } \\
\hline Hubei & Single & Shanyou63 & 115 & 34 & 90 \\
\hline Hunan & Early & Zhefu7 & 95 & 27 & 90 \\
\hline Hunan & Late & Weiyou64 & 177 & 26 & 90 \\
\hline Jiangxi & Early & Ganzaoxian14 & 93 & 24 & 90 \\
\hline Jiangxi & Late & Zhongyougui99 & 177 & 28 & 90 \\
\hline \multicolumn{6}{|l|}{ Souwest } \\
\hline Sichuan & Single & D You63 & 94 & 43 & 90 \\
\hline Chongqing & Single & Eryou & 99 & 41 & 90 \\
\hline Yunnan & Single & Dianza31 & 100 & 34 & 90 \\
\hline Guizhou & Single & Jinyou63 & 107 & 40 & 90 \\
\hline \multicolumn{6}{|l|}{ South } \\
\hline Fujian & Early & Jiayu 164 & 80 & 30 & 100 \\
\hline Fujian & Late & Yixiang2292 & 183 & 26 & 100 \\
\hline Guangdong & Early & SanErAi & 77 & 22 & 90 \\
\hline Guangdong & Late & GuangEr104 & 191 & 22 & 90 \\
\hline Guangxi & Early & Teyou63 & 40 & 22 & 90 \\
\hline Guangxi & Late & Boyou903 & 193 & 23 & 90 \\
\hline Hainan & Early & Teyou63 & 40 & 22 & 90 \\
\hline Hainan & Late & Boyou903 & 193 & 23 & 90 \\
\hline
\end{tabular}




\section{Copyrights}

Copyright for this article is retained by the author(s), with first publication rights granted to the journal.

This is an open-access article distributed under the terms and conditions of the Creative Commons Attribution license (http://creativecommons.org/licenses/by/3.0/). 